\title{
Self-assembled monolayer based impedimetric platform for food borne mycotoxin detection
}

\author{
Pratima Rathee Solanki, ${ }^{a}$ Ajeet Kaushik, ${ }^{a}$ T. Manaka, ${ }^{b}$ Manoj Kumar Pandey, ${ }^{a}$ M. Iwamoto, \\ Ved Varun Agrawal ${ }^{a}$ and Bansi Dhar Malhotra*ac
}

\author{
Received 30th April 2010, Accepted 9th August 2010 \\ DOI: 10.1039/c0nr00289e
}

\begin{abstract}
A self-assembled monolayer (SAM) of 11-amino-1-undecanethiol (AUT) has been fabricated onto a gold $(\mathrm{Au})$ substrate to co-immobilize anti-ochratoxin-A antibodies (AO-IgGs) and bovine serum albumin (BSA) to detect food borne mycotoxin [i.e., ochratoxin-A (OTA)]. AUT/Au electrode, AO-IgGs/AUT/Au immunoelectrode and BSA/IgGs/AUT/Au immunoelectrode have been characterized using scanning electron microscopy (SEM) and electrochemical studies such as cyclic voltammetry (CV), differential pulse voltammetry (DPV) and electrochemical impedance spectroscopy (EIS). Electrochemical studies reveal that the AUT-SAM with $\mathrm{NH}_{2}$ groups provide favorable conditions to immobilize AO-IgGs with better orientation, resulting in enhanced electron transport to obtain improved sensing characteristics. The EIS response studies of the BSA/AO-IgGs/AUT/Au immunoelectrode obtained as a function of OTA concentration reveal that the value of the charge transfer resistance $\left(\mathrm{R}_{\mathrm{CT}}\right)$ increases with increased OTA concentration. The BSA/AO-IgGs/AUT/Au immunoelectrode exhibits linearity over $0.5-6.0 \mathrm{ng} / \mathrm{dl}$, detection limit of $0.08 \mathrm{ng} / \mathrm{dl}$ using $3 \sigma b / m$ criteria, response time of $30 \mathrm{~s}$ and sensitivity of $\sim 36.83 \Omega / \mathrm{ng} \mathrm{dl}^{-1} \mathrm{~cm}^{-2}$ with a regression coefficient of 0.999 . Attempts have been made to monitor the change in $\mathrm{R}_{\mathrm{CT}}$ of BSA/AO-IgGs/AUT/Au immunoelectrode on addition of coffee samples.
\end{abstract}

\section{Introduction}

Electrochemical immunosensors are an important class of sensing systems in clinical diagnosis, food quality control, environmental analysis, detection of pathogens, toxins, explosives and drugs. Among these, impedimetric immunosensors are advantageous due to the small dimensions, low power requirement, low cost and non-destructive steady-state technique that is capable of identifying and separating various contributions from the electric and dielectric response of the material..$^{2-4}$ Moreover, impedimetric sensors provide specificity/selectivity for use in real-world applications with label-free determination of biomolecular affinity coefficients. The impedimetric biosensors have the potential for simple, rapid, label-free, low-cost detection of desired biomolecules. ${ }^{4-6}$

Self-assembled monolayers (SAMs) have recently attracted much attention due to their potential applications in biosensors, nanotechnology and biomolecular electronics. ${ }^{7-9}$ SAMs of organosulfur compounds on gold $(\mathrm{Au})$ have attracted much interest since they offer several advantages such as order, homogeneity, simplicity and are versatile for immobilization of given biomolecules. Moreover, there is a possibility of changing

${ }^{a}$ Department of Science and Technology Centre on Biomolecular Electronics, National Physical Laboratory (Council of Scientific Industrial Research), Dr K. S. Krishnan Marg, New Delhi, 110012, India. E-mail: bansi.malhotra@gmail.com; Fax: +91-11-45609310; Tel: +91-11-45609152

${ }^{b}$ Department of Physical Electronics, Tokyo Institute of Technology, 2-121-S3-33, O-Okayama, Maguro, Tokyo, 152-8552, Japan

${ }^{c}$ Centre for Nano-Bioengineering and Spintronics, Chungnam National University, Daejeon, 305-764, Korea the tail group enabling control of the surface structure of a SAM. ${ }^{10,11}$ In an electrochemical sensor, SAMs can be used as insulating barriers between an electrode and a redox couple for investigating long range electron-transfer and to measure fast electron-transfer kinetics. A variety of SAMs based biosensors have been developed for detection of food pathogens (mycotoxin i.e., ochratoxin A (OTA)), ${ }^{12}$ environmental monitoring ${ }^{13}$ and clinical analysis etc. ${ }^{\mathbf{1 1 , 1 4}}$

OTA is a food contaminating mycotoxin produced by Aspergillus ochraceus and other stains of Aspergillus niger and Penicillium verrucosum. ${ }^{15,16}$ The presence of OTA has been reported in various agriculture crops such as cereals, pulses, coffee beans in animal feed as well as in tissues and blood of living beings. It has been found that OTA causes nephrotoxin, carcinogenic, genotoxic, immunosuppressive and teratogenic. ${ }^{17,18}$ Conventional techniques ${ }^{19-31}$ used for OTA detection require multiple steps including extraction, extensive sample clean-up, preconcentration, and sometimes derivatization of the desired analyte. In this context, electrochemical impedance spectroscopy (EIS) based immunosensors have been considered significant for rapid, sensitive and selective detection with improved stability and orientation of the electrode bound antibodies.

Electrochemical immunosensors based on conducting polymers, nanomaterials and nanocomposites have been used for OTA detection. Kaushik et al. 2009 have used sol-gel derived nanostructured cerium oxide films and chitosan (CS)-iron oxide nanocomposites to immobilize IgGs antibodies for OTA detection using differential pulse voltammetry (DPV) technique. ${ }^{27,28}$ Khan et al. have fabricated CS-polyaniline hybrid conducting biopolymer films and CS-titanium nanocomposite films for the immobilization of IgGs for OTA detection..$^{29,30}$ Sol-gel derived 
nanostructured zinc oxide films have been used for co-immobilization of IgGs and BSA to detect OTA. ${ }^{31}$ A 4-carboxyphenyl film grafted onto a Au electrode by electrochemical reduction of in situ generated 4-carboxyphenyl diazonium salt (4-CPDS) has been used for immobilization of the antibodies for OTA detection using EIS. ${ }^{32}$ A self-assembled monolayer (SAM) of 1,6hexanedithiol that mediates the assembly of a Au colloid layer has been utilized for immobilization of alkaline phosphatase labeled horse anti-mouse immunoglobulin $\mathrm{G}$ antibody for OTA detection. ${ }^{33}$ Quartz crystal microbalance based on a 16-mercaptohexadecanoic (16-MHDA) acid immunosensor has been reported for immobilization of AO-OTA IgGs for detection of OTA. ${ }^{23}$

In this manuscript, we report results of the studies relating to the co-immobilization of AO-IgGs and BSA onto $\mathrm{NH}_{2}$ terminal SAM of 11-amino-1-undecanethiol (AUT) to detect OTA using EIS.

\section{Results and discussion}

Surface morphology studies of AUT/Au electrode, AO-IgGs/ AUT/Au immunoelectrode and BSA/AO-IgG/AUT/Au immunoelectrode have been carried out using a scanning electron microscope (SEM, Fig. 1A-C). The planar smooth morphology of the AUT/Au electrode (Fig. 1A) changes into an uniformly distributed granular morphology (Fig. 1B) revealing the immobilization of the AO-IgGs onto the AUT/Au electrode. After the immobilization of BSA onto the AO-IgGs/AUT/Au immunoelectrode, the granular morphology of the AO-IgGs/ AUT/Au immunoelectrode changes into a rough and globular morphology (Fig. 1C) indicating immobilization of BSA and blocking of non-binding sites of the AO-IgGs/AUT/Au immunoelectrode for OTA adsorption.

The contact angle studies of AUT/Au electrode, AO-IgGs/ AUT/Au immunoelectrode and BSA/AO-IgGs/AUT/Au immunoelectrode have been conducted using the Sessile drop method to assess the hydrophobic/hydrophilic nature of the surface. The value of the contact angle measured as $80^{\circ}$ for the bare gold ( $\mathrm{Au}$ ) surface indicates both a clean as well as hydrophobic nature of the surface. The contact angle value decreases to $67^{\circ}$ after the SAM formation on the gold surface, due to the presence of the $\mathrm{NH}_{2}$ groups of the AUT molecule on the gold substrate. Further, the contact angle value decreases to $55^{\circ}$ and $37.78^{\circ}$ in the case of the AO-IgGs/AUT/Au and BSA/AO-IgGs/AUT/Au immunoelectrode, respectively, due to hydrophilic nature of the protein (AO-IgGs and BSA) onto the AUT/Au surface.

To obtain an immunosensor with improved sensing characteristics, the carboxyl terminated group [fragment crystallisable $\left(F_{c}\right)$ ] of IgGs should be bind to electrode via electrostatic interactions and the free amino terminated site [fragment antigen binding $\left(\mathrm{F}_{\mathrm{ab}}\right)$ ] part are free to bind with the antigen with high level of specificity. In our Scheme (Fig. 1D), the $\mathrm{NH}_{2}$ group of
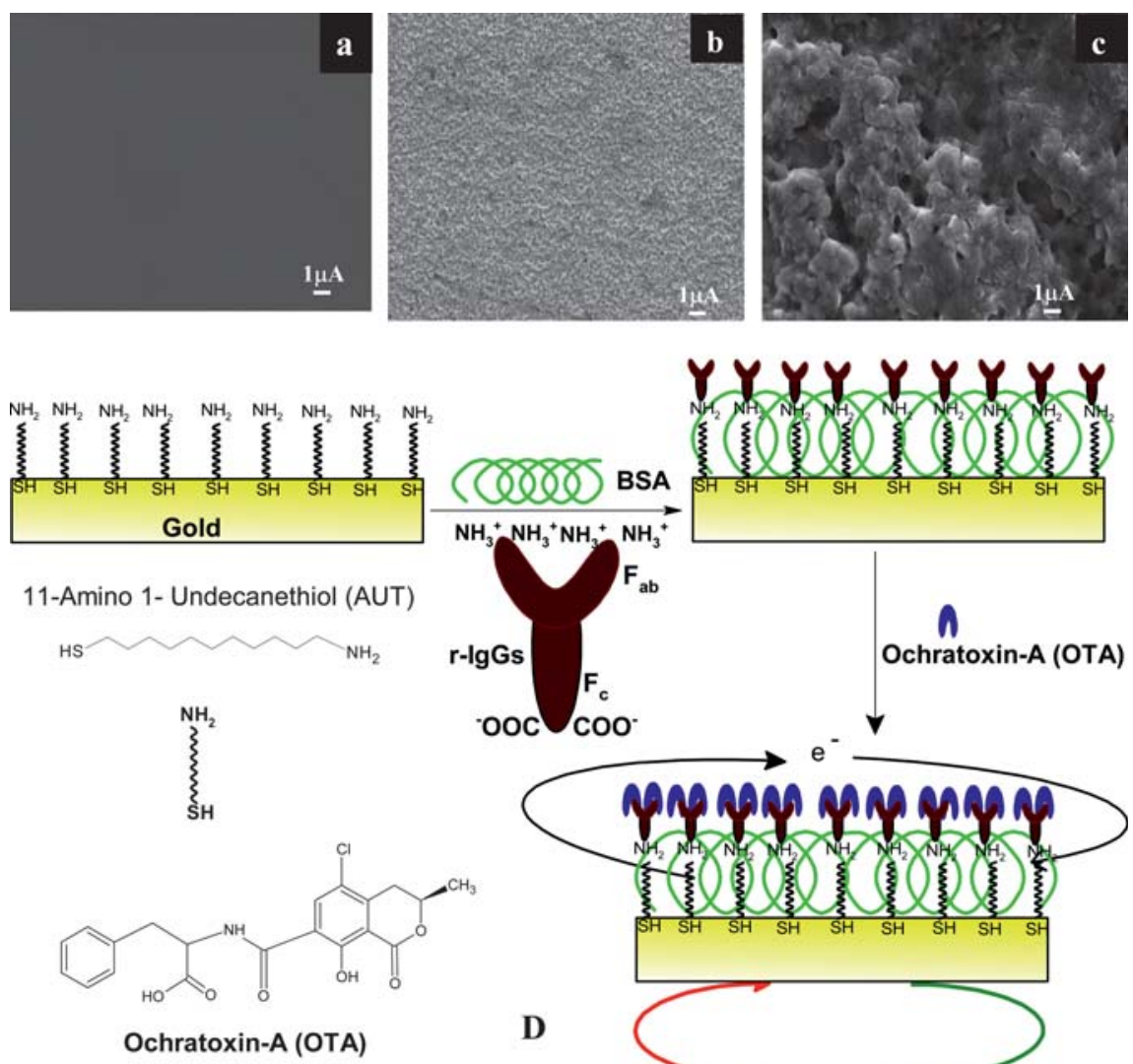

D

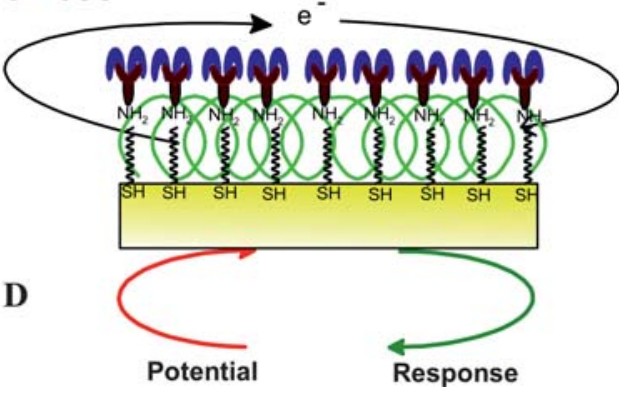

Fig. 1 A) SEM image of the AUT/Au electrode, B) SEM image of the AO-IgGs/AUT/Au immunoelectrode, C) SEM image of the BSA/AO-IgGs/ AUT/Au immunoelectrode, D) Schematic for the fabrication of the BSA/AO-IgGs/AUT/Au immunosensor showing the biochemical reaction at the BSA/AO-IgGs/AUT/Au immunoelectrode. 

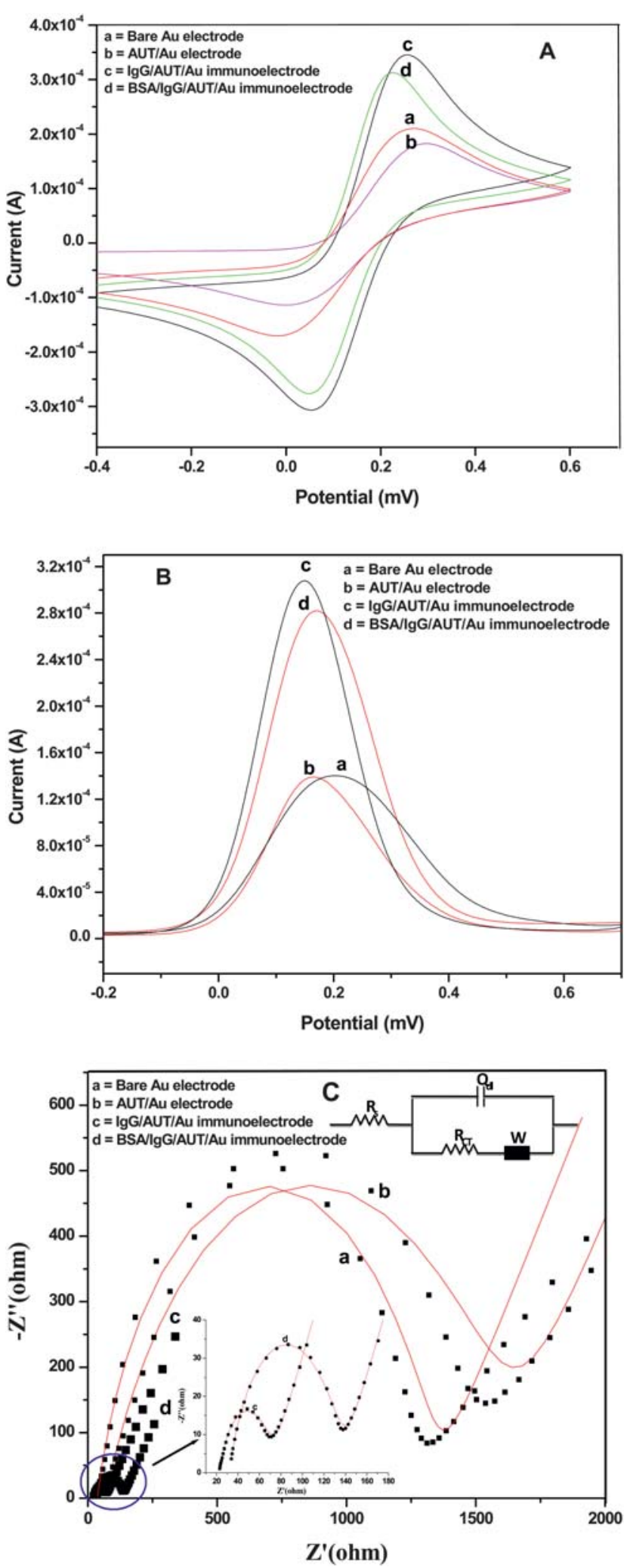

Fig. 2 A) Cyclic voltammogram of the modified SAM with IgGs at a scan rate of $50 \mathrm{mV} / \mathrm{s}$ in PBS containing $\left[\mathrm{Fe}(\mathrm{CN})_{6}\right]^{3-/ 4-}$. B) Differential pulse voltammogram (DPV) of the bare Au electrode (a), AUT/Au electrode (b), AO-IgGs/AUT/Au bioelectrode (c) and BSA/AO-IgGs/ AUT/Au immunoelectrode (d) at potential height as $0.4995 \mathrm{~V}$, potential period as $0.07 \mathrm{~ms}$ and interval period as $0.14 \mathrm{~ms}$ in PBS containing $\left[\mathrm{Fe}(\mathrm{CN})_{6}\right]^{3-14-}$. C) EIS studies of bare $\mathrm{Au}$ electrode (a), AUT/Au
AUT-SAM binds with the carboxyl groups $\left(\mathrm{F}_{\mathrm{c}}\right)$ of AO-IgGs via electrostatic interactions and the free amino terminal sites of AO- $\operatorname{IgG}\left(\mathrm{F}_{\mathrm{ab}}\right)$ preferably bind with the carboxylic group of the OTA molecules via hydrogen bonding, ionic bands and van der Waals forces.

Fig. 2A shows results of the cyclic voltammetry (CV) studies conducted on the bare gold $(\mathrm{Au})$ electrode, AUT/Au electrode, AO-IgGs/AUT/Au immunoelectrode, and BSA/AO-IgGs/AUT/ Au immunoelectrode in PBS $\{50 \mathrm{mM}, \mathrm{pH}=7.4$ containing $0.9 \%$ $\mathrm{NaCl}$ and $\left.5 \mathrm{mM}\left[\mathrm{Fe}(\mathrm{CN})_{6}\right]^{3-/ 4-}\right\}$. The magnitude of electrochemical current response of the AUT/Au electrode (18.5 mA, Curve b) is lower than that of the bare Au electrode $(21 \mathrm{~mA}$, Curve a), revealing the formation of AUT-SAM that hinders electron transfer from medium to Au electrode. However, the magnitude of the response current increases to $34.57 \mathrm{~mA}$ (Fig. 2A, Curve c) after the immobilization of AO-IgGs onto the AUT/Au electrode. It appears that an available $\mathrm{NH}_{2}$ group of the AUT-SAM binds with the carboxyl group $\left(\mathrm{F}_{\mathrm{c}}\right.$, terminal) of AO-IgGs and the presence of free $\mathrm{NH}_{3}{ }^{+}$groups of AO-IgGs $\left(\mathrm{F}_{\mathrm{ab}}\right.$, terminal) leading to increased diffusion of electrons onto the $\mathrm{AO}-\mathrm{IgGs} / \mathrm{AUT} / \mathrm{Au}$ electrode that, in turn, results in easier electron communication to the electrode surface. Moreover, the magnitude of current response decreases to $31.35 \mathrm{~mA}$ with a slight shift of the redox potential towards the lower side on immobilization of BSA (Fig. 2; Curve d) onto the AO-IgGs/ AUT/Au immunoelectrode, due to blocking of non-binding sites of IgGs that hinder electron transfer between medium and electrode, indicating immobilization of BSA onto the AO-IgGs/ AUT/Au bioelectrode.

The results obtained from the CV studies have been correlated with those obtained with differential pulse voltammetry (DPV, Fig. 2B). The magnitude of the current response of the AUT/Au (Curve b) electrode is lower than that of the Au electrode (Curve a). However, magnitude of the current response of the IgGs/ AUT/Au immunoelectrode (Curve c) is higher than that of AUT/ Au electrode (Curve c), due to the availability of the non-binding sites on $\mathrm{IgGs}$ resulting in enhanced electron transport between medium and electrode. The magnitude of the current response of the BSA/AO-IgGs/AUT/Au immunoelectrode (Curve d) is lower than that of AO-IgGs/AUT/Au immunoelectrode due to blocking of non-specific bonding sites of AO-IgGs that perhaps insulate the electrode and perturb electron communication.

The EIS provides an effective method for probing electrical characteristics of the desired surface modified electrode. A smallamplitude perturbing sinusoidal voltage signal is applied to the electrochemical cell and the resulting current is measured. The impedance is calculated as the ratio between the system voltage phasor, $\mathrm{U}(\mathrm{j} \omega)$, and the current phasor, $I(\mathrm{j} \omega)$, that are generated by a frequency response analyzer during the experiments. ${ }^{5,34,35}$ The complex impedance can be presented as a combination of the real, $Z_{\mathrm{re}}(\omega)$, and imaginary, $\mathrm{Z}_{\mathrm{im}}(\omega)$ components that originate

electrode (b), IgGs/AUT/Au immunoelectrode (c), BSA/AO-IgGs/AUT/ $\mathrm{Au}$ immunoelectrode $(\mathrm{d})$ in PBS containing $\left[\mathrm{Fe}(\mathrm{CN})_{6}\right]^{3-/ 4-}$. Red lines indicate the simulated curves obtained by fitting model of proposed electronic circuit. Inset A shows the EIS spectra of the IgGs/AUT/Au immunoelectrode (c), BSA/AO-IgGs/AUT/Au immunoelectrode (d). 
mainly from resistance and capacitance of the cell that can be calculated using eqn (1).

$$
\mathrm{Z} \omega=\mathrm{U}(\mathrm{j} \omega) / \mathrm{I}(\mathrm{j} \omega)=\mathrm{Z}_{\mathrm{re}}(\omega)+\mathrm{j} \mathrm{Z}_{\mathrm{im}}(\omega) \text {; where } \omega=2 \pi \mathrm{f} \text { (Eq. 1) }
$$

A typical shape of the faradic impedance spectrum (presented in the form of the Nyquist plot) includes a semicircle region lying on the $Z_{\text {re }}(\omega)$ axis followed by a straight line. The semicircle portion, observed at higher frequency, yields the electron transfer resistance $\left(R_{C T}\right)$, that exhibits electron transfer kinetics of the redox probe at the electrode interface, whereas linear part represents the diffusion process. ${ }^{34-36}$ This semicircle also represents the response of heterogeneous charge transfer kinetics (eqn (2) \& 3).

$$
\begin{aligned}
\mathrm{RC} & =\mathrm{RT} / \mathrm{nFI}_{0} \\
\mathrm{I}_{0} & =\mathrm{nFA} k^{0} \mathrm{C}
\end{aligned}
$$

where $R$ is the gas constant, $T$ is the temperature, $n$ is the electron transfer constant of the redox couple, $\{n=1$ as for $\left.\left[\mathrm{Fe}(\mathrm{CN})_{6}\right]^{3-/ 4-}\right\}, F$ is the Faraday constant, $\mathrm{I}_{0}$ is the exchange current between the gold electrode and the redox couple, $A$ is the area of gold electrode, $k^{0}$ is the charge transfer rate constant and $C$ is the concentration of the redox couple. The value of the charge transfer rate constant can be obtained from eqn (1) and eqn (2). The curve simulated by equivalent circuit is close to the experimental impedance plot, which indicates that the equivalent circuit is accurate.

Fig. 2C shows the EIS spectra simulated by the electronic circuit $R_{s}\left[Q_{d L}\left(R_{C T} W\right)\right]$ [inset, Fig. $2 C$ ] for the bare Au electrode, AUT/Au electrode and BSA/AO-IgGs/AUT/Au immunoelectrode. It can be seen that $R_{C T}$ of the AUT/Au electrode is larger than (1.42 K $\Omega$, Curve $b$ ) that of the bare gold electrode (Curve a) $(1.21 \mathrm{~K} \Omega)$. This may be attributed due to the formation of the monolayer on the $\mathrm{Au}$ surface that hinders direct electron flow from the redox probe $\left[\mathrm{Fe}(\mathrm{CN})_{6}\right]^{3-/ 4-}$ to the electrode surface. Further, the $\mathrm{R}_{\mathrm{CT}}$ value decreases to $0.052 \mathrm{~K} \Omega$ (Curve c) after the immobilization of $\mathrm{AO}-\mathrm{IgGs}$ onto AUT/Au electrode revealing immobilization of AO-IgGs onto AUT/Au electrode. It appears that of IgGs cationic AO-IgGs/AUT/Au facilitate electron communication between the redox probe $[\mathrm{Fe}(\mathrm{III}) / \mathrm{Fe}(\mathrm{IV})]$ and the electrolyte. Moreover, the value of $\mathrm{R}_{\mathrm{CT}}$ increases to $0.115 \mathrm{~K} \Omega$ after immobilization of BSA onto the AO-IgGs/AUT/Au immunoelectrode (Curve d) revealing that insulating BSA layer perhaps hinders diffusion of ferricyanide ions toward the electrode surface. The observed change in $\mathrm{R}_{\mathrm{CT}}$ after BSA immobilization can be assigned to the dielectric changes and insulating features at the electrode-electrolyte interface arising due to successive immobilization of biomolecules. The immobilized BSA blocks non-specific sites of AO-IgGs/AUT/Au immuonelectrode for adsorption of OTA.

The electrochemical impedimetric response of the BSA/ $\mathrm{AO}-\mathrm{IgGs} / \mathrm{AUT} / \mathrm{Au}$ immunoelectrode has been investigated as a function of OTA concentration $\left(0.5-6.0 \mathrm{ngdL}^{-1}\right)$ in PBS containing $\left[\mathrm{Fe}(\mathrm{CN})_{6}\right]^{3-14-}$ with incubation time of $30 \mathrm{~s} \mathrm{(Fig.} \mathrm{3A).} \mathrm{It}$ has been found that the $\mathrm{R}_{\mathrm{CT}}$ value increases linearly on addition of OTA concentration onto BSA/AO-IgGs/AUT/Au immunoelectrode (Fig. 3B). The increased $\mathrm{R}_{\mathrm{CT}}$ value indicates blocking
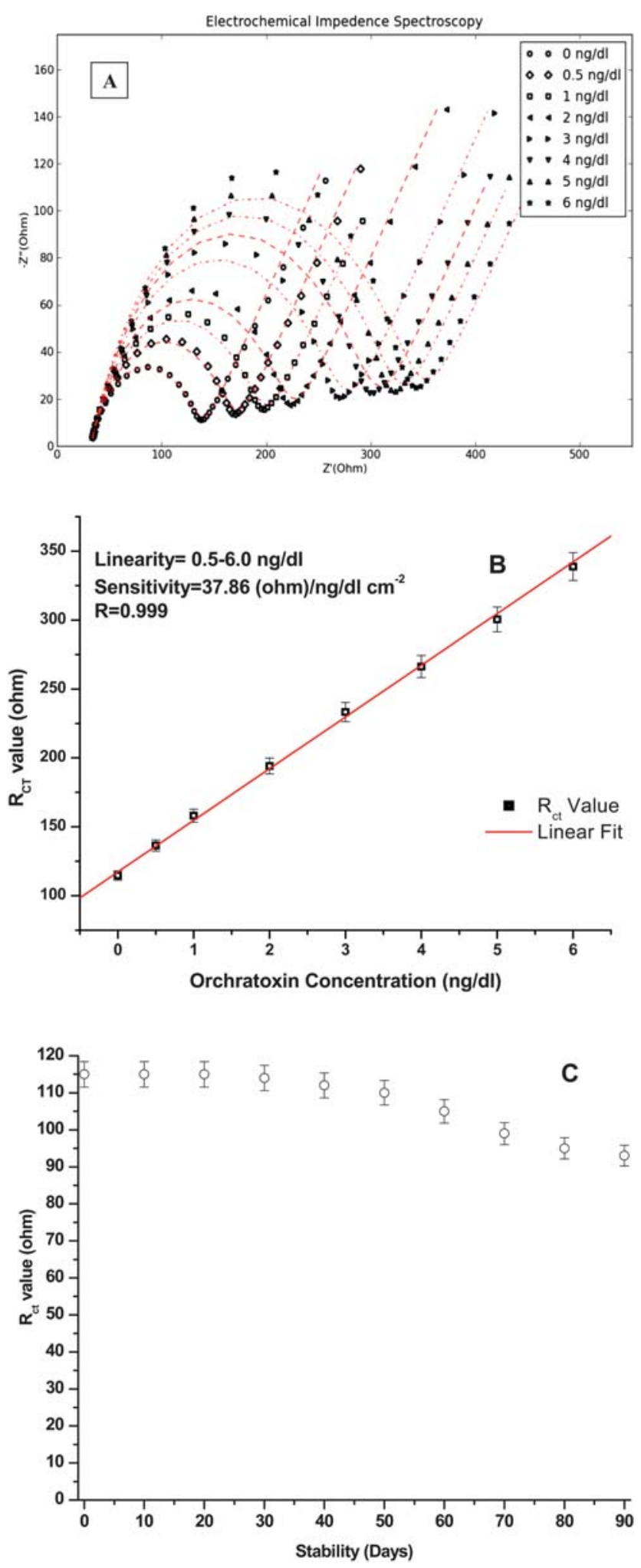

Fig. 3 A) Sensing characteristics of the BSA/AO-IgGs/AUT/Au bioelectrode as a function of OTA using electrochemical impedance spectroscopy technique in PBS containing $\left[\mathrm{Fe}(\mathrm{CN})_{6}\right]^{3-14-}$. Red lines indicate the simulated curves obtained by fitting model of proposed electronic circuit. B) Calibration curve obtained between the $\mathrm{R}_{\mathrm{CT}}(\Omega)$ value versus OTA concentration $\left(\mathrm{ng} \mathrm{dl}^{-1}\right)$. C) Stability studies of the BSA/AO-IgGs/ AUT/Au bioelectrode. 
behavior of the redox couple. It appears that transfer of $\left[\mathrm{Fe}(\mathrm{CN})_{6}\right]^{3-14-}$ redox ions is blocked due to formation of highly organized layers on the electrode surface because these redox species do not penetrate the layer and enter into the conductive electrode surface. In general, the charge transfer rate constant $k^{0}$ indicates an electrical barrier that can be reflected by the electron transfer resistance of the redox probe of $\left[\mathrm{Fe}(\mathrm{CN})_{6}\right]^{3-/ 4-}$. On exposure of the BSA/AO-IgGs/AUT/Au immunoelectrode to OTA molecules, the presence of an insulating layer formed on the electrode results in increased diameter of the semicircle, implying high electron transfer resistance. The diameter becomes larger and the charge transfer rate constant $k^{0}$ diminishes. The EIS curve obtained as a function of OTA concentration has been simulated by electronic circuit $\mathrm{R}_{\mathrm{s}}\left(\mathrm{Q}_{\mathrm{dL}}\left(\mathrm{R}_{\mathrm{CT}} \mathrm{W}\right)\right.$ and the generated curves are represented as lines (red) to show goodness of fit in Fig. 3A.

As shown in the Schematic (Fig. 1E), the free amino groups of BSA/AO-IgGs/AUT/Au immunoelectrode have the affinity to bind with the carboxylic group of OTA molecules. Fig. 3B shows the calibration curve obtained between $\mathrm{R}_{\mathrm{CT}}$ and the OTA concentration. A linear relationship between the $\mathrm{R}_{\mathrm{CT}}$ value and the OTA concentration is obtained as $0.5-6 \mathrm{ng} \mathrm{dL}^{-1}$. The linear equation obtained is: $\mathrm{R}_{\mathrm{CT}}(\Omega)=115(\Omega)+36.83 \Omega \mathrm{dL}^{-1} \mathrm{ng}^{-1} \times$ OTA concentration (ng/dl). The sensitivity of this BSA/ AO-IgGs/AUT/Au immunoelectrode obtained is 36.83 ( $(\Omega) /$ $\mathrm{ngdL} \mathrm{Cm}^{-1}$ with a value of the linear regression coefficient $\left(\mathrm{r}^{2}\right)$ as 0.999. It was found that the BSA/AO-IgGs/AUT/Au immunoelectrode shows improved characteristics such as response time as $30 \mathrm{~s}$, good reproducibility ( $>20$ times). The detection limit has been estimated as $0.08 \mathrm{ng} / \mathrm{dl}$ using $3 \sigma b / m$ criteria, where $m$ is slope of the calibration graph and $\sigma b$ is standard deviation of the blank signal. The high value of association constant $\left(\mathrm{K}_{\mathrm{a}}, 3.96 \times\right.$ $10^{11} \mathrm{~L} \mathrm{~mol}^{-1}$ ) indicates high affinity of AO-IgG towards OTA to prevalent specific interactions. ${ }^{27}$ It may be noted that the conformational changes of antibodies affect the biological reaction that occurs at the AUT/Au immunoelectrode surface. The increased activity of the AO-IgGs onto AUT/Au electrode due to $\mathrm{IgGs}$ with favourable orientation resulting in enhanced interaction between AUT/Au electrode and the active site of AO-IgGs as indicated by the higher $\mathrm{K}_{\mathrm{a}}$ value.

The $\mathrm{R}_{\mathrm{CT}}$ value has been found to change after the initialization of electrode with different concentrations of OTA. Thus, the sensitivity of the immunoelectrode can be determined with relative change in the $R_{C T}$ value.
Relative Sensitivity $=100\left[\mathrm{R}_{\mathrm{CT}}(\mathrm{x})-\mathrm{R}_{\mathrm{CT}}(0)\right] / \mathrm{R}_{\mathrm{CT}}(\mathrm{x})$ (Eq. 4)

where, $\mathrm{R}_{\mathrm{CT}}(\mathrm{x})$ and $\mathrm{R}_{\mathrm{CT}}(0)$ are the value of $\mathrm{R}_{\mathrm{CT}}$ for 0 and ' $x$ ' $\mathrm{ng}$ / $\mathrm{mL}$ concentration of OTA in the electrolyte. The relative sensitivity of BSA/AO-IgGs/AUT/Au immunoelectrode obtained is $54.87 \Omega \mathrm{dl} \mathrm{ml}^{-1}$. The interaction of OTA with the immunoelectrode depends on the relative proportion and the activities of AO-IgGs molecules at the surface. This immunoelectrode exhibits excellent sensitivity, resulting in higher number of $\mathrm{NH}_{2}$ groups on the AUT/Au electrode that supports the AO-IgGs with increased activity. The characteristics of the BSA/AO-IgG/ AUT/Au immunoelectrode along with those reported in literature are summarized in Table 1.

The storage stability of the BSA/AO-IgGs/AUT/Au immunoelectrode has been determined by observing the $\mathrm{R}_{\mathrm{CT}}$ value at regular intervals of 10 days for about 90 days (Fig. 3C). The BSA/AO-IgGs/AUT/Au immunoelectrode is stored at $4{ }^{\circ} \mathrm{C}$ when not in use. It has been found that the bioelectrode exhibits a $95 \%$ response up to 45 days. After that, the $\mathrm{R}_{\mathrm{CT}}$ value decreases and reaches $82 \%$ of $R_{C T}$ in 90 days.

Attempts have been made to monitor response of the BSA/ AO-IgGs/AUT/Au immunoelectrode in instant coffee samples

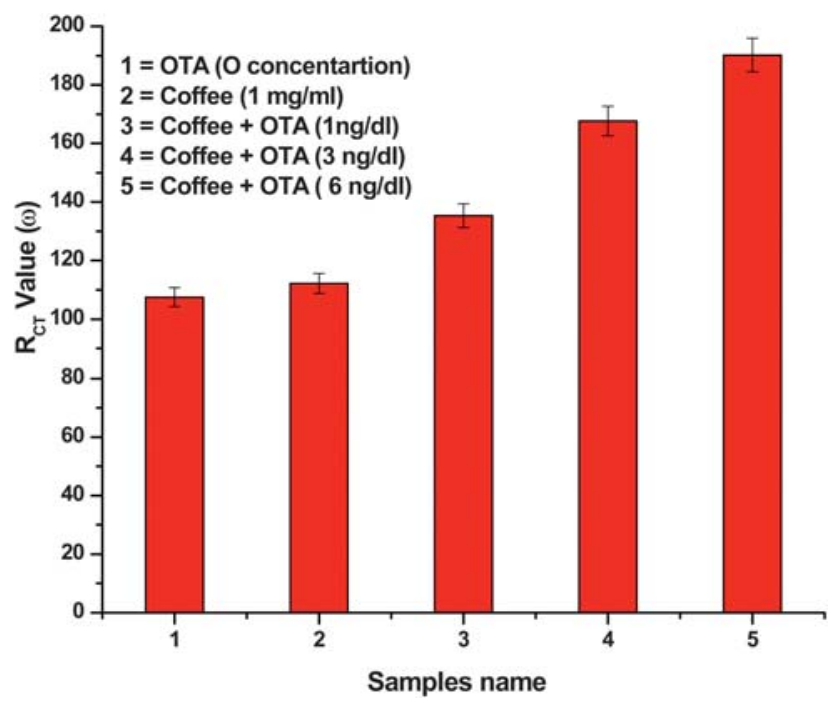

Fig. 4 The bar chart of $\mathrm{R}_{\mathrm{CT}}$ values obtained for coffee sample with addition of OTA concentration.

Table 1 Biosensing characteristics of the BSA/IgGs/AUT/Au immunoelectrode along with those reported in the literature

\begin{tabular}{|c|c|c|c|c|c|c|}
\hline Immunosensing Platform & Techniques & Linear Range & Detection Limit & Sensitivity & Shelf-life & Ref. \\
\hline $\mathrm{NanoCeO}_{2}$ & DPV & $0.5-6 \mathrm{ng} / \mathrm{dL}$ & $0.5 \mathrm{ng} / \mathrm{dL}$ & $1.27 \mu \mathrm{A} / \mathrm{ng} \mathrm{dL}^{-1} \mathrm{~cm}^{-2}$ & 80 days & 27 \\
\hline $\mathrm{CS}-\mathrm{TiO}_{2}$ & - & $1-10 \mathrm{ng} / \mathrm{mL}$ & $1 \mathrm{ng} / \mathrm{mL}$ & - & - & 29 \\
\hline Polyaniline-CS & EIS & $1-10 \mathrm{ng} / \mathrm{mL}$ & $1 \mathrm{ng} / \mathrm{mL}$ & $53 \Omega \mathrm{mL} / \mathrm{ng}$ & - & 30 \\
\hline NanoZnO & EIS & $0.006-0.01 \mathrm{nM} / \mathrm{dm}^{3}$ & $0.006 \mathrm{nM} / \mathrm{dm}^{3}$ & $189 \Omega / \mathrm{nM} / \mathrm{dm}^{3} \mathrm{~cm}^{2}$ & 45 days & 31 \\
\hline 4-carboxyphenyl & EIS & $1-20 \mathrm{ng} / \mathrm{mL}$ & $0.5 \mathrm{ng} / \mathrm{mL}$ & - & 12 days & 32 \\
\hline
\end{tabular}


Table 2 Effect of other mycotoxin (aflatoxin) onto the BSA/IgGs/AUT/ Au immunoelectrode

\begin{tabular}{llllll}
\hline & $\begin{array}{l}\text { OTA } \\
\text { concentration } \\
\text { (ng/dl) }\end{array}$ & $\mathrm{R}_{\mathrm{CT}}$ & $\begin{array}{l}\text { OTA }+ \\
\text { Aflatoxin } \mathrm{B}_{1} \\
\text { concentration } \\
\text { (ng/dl) }\end{array}$ & $\mathrm{R}_{\mathrm{CT}}$ & $\begin{array}{l}\text { Relative } \\
\text { Difference (\%) }\end{array}$ \\
\hline 1 & 3.0 & 233.3 & $3.0+1.0$ & 242.4 & 1.72 \\
2 & 3.0 & 240.2 & $3.0+2.0$ & 245.5 & 2.2 \\
3 & 3.0 & 239.4 & $3.0+3.0$ & 244.6 & 2.17 \\
\hline
\end{tabular}

(100\% Pure Nescafe). During these experiments, the BSA/ $\mathrm{AO}-\mathrm{IgGs} / \mathrm{AUT} / \mathrm{Au}$ immunoelectrode is dipped in the reaction mixture and an equal amount of OTA and instant coffee sample are added and are kept for $30 \mathrm{~s}$. The EIS spectra have been recorded under similar conditions and the $\mathrm{R}_{\mathrm{CT}}$ value calculated according to software. It has been found that the $\mathrm{R}_{\mathrm{CT}}$ value of the BSA/AO-IgGs/AUT/Au immunoelectrode as a function of coffee remains the same as in samples containing OTA concentrations. Moreover, the $\mathrm{R}_{\mathrm{CT}}$ of the BSA/AO-IgGs/AUT/Au immunoelectrode changes when the coffee sample contains OTA and value of the $\mathrm{R}_{\mathrm{CT}}$ further increases as the OTA concentration increases in the coffee sample (Fig. 4), revealing that the BSA/ AO-IgGs/AUT/Au immunoelectrode shows additive effect.

To estimate the specificity of the developed BSA/AO-IgGs/ AUT/Au immunosensor, the influence of aflatoxin (mycotoxin) was investigated using EIS technique. The specificity of the BSA/ AO-IgGs/AUT/Au immunoelectrode was monitored using different concentrations of aflatoxin $(1-3 \mathrm{ng} / \mathrm{dl})$. It has been observed that the $\mathrm{R}_{\mathrm{CT}}$ value changes in terms of relative difference below 5\% (Table 2). Therefore, the developed BSA/ AO-IgGs/AUT/Au immunoelectrode shows high selectivity for OTA detection.

\section{Conclusions}

AO-IgGs and BSA have been co-immobilized onto an AUT/Au SAM for the fabrication of an immunosensor for OTA detection. The BSA/AO-IgGs/AUT/Au immunoelectrode can be utilized to estimate OTA $(0.5-6.0 \mathrm{ng} / \mathrm{dl})$ using EIS. It has been shown that the $\mathrm{NH}_{2}$ terminal AUT provides a favorable environment for the immobilization of IgGs resulting in enhanced electron transfer between AO-IgGs and the redox probe. The BSA/AO-IgGs/ AUT/Au immunoelectrode represents a new impedimetric immuno-platform that can be used for detection of other food mycotoxins such as aflatoxin, ochratoxin B, citrinin, ergot akaloids, fumonisins, patulin, trichothecenes, and zearalenone etc.

\section{Experimental section}

\section{Materials}

Anti ochratoxin antibodies (IgGs) were purchased from Genxbio, India. Bovin serum albumin (BSA) and 11-amino-1-undecanethiol hydrochloride were procured from Sigma Aldrich (USA). To prepare a $\mathrm{NH}_{2}$ terminal self-assembled monolayer onto a gold surface, $1 \mathrm{mM}$ 11-amino-1-undecanethiol hydrochloride was dissolved in ethanol. All other chemicals were of analytical grade and were used without further purification.
Fabrication of 11-amino-1-undecanethiol (AUT) self assembled monolayer and BSA/AO-IgGs/AUT/Au immunoelectrode

SAM of 11-amino-1-undecanethiol (AUT) was fabricated by immersion of the pre-cleaned gold $(\mathrm{Au})$ substrate into a $1 \mathrm{mM}$ ethanol solution of 11-amino-1-undecanethiol hydrochloride for $24 \mathrm{~h}$ at $25^{\circ} \mathrm{C}$. The SAM modified Au plates were rinsed with ethanol and water several times and dried under a stream of nitrogen. These AUT/Au electrodes were used for the coimmobilization of AO-IgGs and BSA to fabricate the OTA immunosensor.

Anti-OTA antibodies (IgGs, $1 \mathrm{mg} / \mathrm{ml}$ ) solution was prepared in $50 \mathrm{mM}$ phosphate buffer $\{(\mathrm{PB}), 50 \mathrm{mM}, \mathrm{pH} 7.4\}$ and a $0.15 \mathrm{M}$ $\mathrm{NaN}_{3}$ was used as a preservative. The OTA (Aspergillus ochraceus) solution was prepared in phosphate buffer $(50 \mathrm{mM}, \mathrm{pH} 7.4)$ with $10 \%$ methanol and stored at $-20{ }^{\circ} \mathrm{C}$. A solution of bovine serum albumin (BSA, $2 \mathrm{mg} / \mathrm{mL}$ ) was prepared in phosphate buffer (50 mM, pH 7.0) and used as blocking agent for nonspecific binding sites. AO-IgGs were immobilized onto AUTSAM by dispensing AO-IgGs $(10 \mu \mathrm{L})$ by keeping these for about $12 \mathrm{~h}$ at room temperature. The resulting AO-IgGs/AUT/Au bioelectrodes were washed with phosphate buffer saline (PBS) $(50 \mathrm{mM}, \mathrm{pH} 7.4,0.9 \% \mathrm{NaCl})$ to remove any unbound antibodies. The prepared AO-IgGs/AUT/Au immunoelectrode was immersed in BSA for $4 \mathrm{~h}$ to block non-specific sites for OTA adsorption. The BSA/AO-IgGs/AUT/Au immunoelectrode was stored at $4{ }^{\circ} \mathrm{C}$ when not in use.

The electrochemical experiments with the AUT/Au electrode were repeated in triplicate. It was found that the results are reproducible within $1 \%$ variation, indicating that the AUT/Au electrode was stable and can be used at least 15 times.

The activity of the BSA/AO-IgGs/AUT/Au immunoelectrode was estimated as a function of $\mathrm{pH}$ varying from 6.0 to 8.0 at room temperature $\left(25^{\circ} \mathrm{C}\right)$. The high magnitude of current found to be maximum at $\mathrm{pH} 7.4$ (data not shown) indicates that the $\mathrm{BSA} / \mathrm{IgG} / \mathrm{AUT} / \mathrm{Au}$ immunoelectrode is more active at $\mathrm{pH} 7.4$ at which IgGs and BSA retain their natural structures and do not denature. Thus all the experiments were conducted at $\mathrm{pH}$ 7.4.

\section{Instrumentation}

Scanning electron microscope (SEM, LEO-440), and contact angle studies were used for characterization of the AUT/Au electrode and the BSA/AO-IgGs/AUT/Au immunoelectrode. The electrochemical studies such as cyclic voltammetry (CV), differential pulse voltammetry (DPV) and electrochemical impedance spectroscopy (EIS) of the AUT/Au electrode and the BSA/AO-IgGs/AUT/Au immunoelectrode were conducted on an Autolab Potentiostat/Galvanostat (Eco Chemie, Netherlands) using a three-electrode system with gold as the working electrode, platinum $(\mathrm{Pt})$ wire as the auxiliary electrode and $\mathrm{Ag} /$ $\mathrm{AgCl}$ as the reference electrode in PBS (50 mM, pH 7.4, 0.9\% $\mathrm{NaCl})$ containing $5 \mathrm{mM}\left[\mathrm{Fe}(\mathrm{CN})_{6}\right]^{3-14-}$.

\section{Acknowledgements}

We thank Dr R. C. Budhani, Director, National Physical Laboratory, New Delhi, India for the facilities. PRS and AK are grateful to the Department of Science and Technology (DST), India for financial support. We acknowledge financial support 
received from the DST projects [DST/TSG/ME/2008/18 and SR/ FT/ET-070/2008] and the Department of Biotechnology, Govt. of India (DBT/GAP070832).

\section{References}

1 S. Fujii, E. Y. S. Ono, R. M. R. Ribeiro, F. G. A. Assuncao, C. R. Takabayashi, T. C. R. M. Oliveira, E. N. Itano, Y. Ueno, O. Kawamura and E. Y. Hirooka, Brazilian Archives of Biology and Technology. Vol. 50, no. 2: pp.349-359, March 2007.

2 S. Hleli, C. Martelet, A. Abdelghani, N. Burais and N. J. Renult, Sens. Actuators, B, 2006, 113, 711.

3 J. G. Guan, Y. Q. Miao and Q. J. Zhang, J. Biosci. Bioengin., 2004, 97, 219.

4 C. Dhand, P. R. Solanki, K. N. Sood, M. Datta and B. D. Malhotra, Electrochem. Commun., 2009, 11, 1482.

5 E. Katz and I. Willner, Electroanalysis, 2003, 15, 913.

6 X. Yu, R. Lv, Z. Ma, Z. Liu, Y. Hao, Q. Li and D. Xu, Analyst, 2006, 131, 745.

7 S. K. Arya, A. K. Prusty, S. P. Singh, P. R. Solanki, M. K. Pandey, M. Datta and B. D. Malhotra, Anal. Biochem., 2007, 363, 210.

8 J. Sagiv, J. Am. Chem. Soc., 1980, 102, 92.

9 D. L. Allara and R. G. Nuzzo, Langmuir, 1985, 1, 45.

10 S. K. Arya, P. R. Solanki, M. Datta and B. D. Malhotra, Biosens. Bioelectron., 2009, 24, 2810.

11 P. R. Solanki, S. K. Arya, Y. Nishimura, M. Iwamoto and B. D. Malhotra, Langmuir, 2007, 23, 7398.

12 F. Ricci, G. Volpe, L. Micheli and G. Palleshi, Anal. Chim. Acta, 2007, 165, 111

13 P. R. Solanki, N. Prabhakar, M. K. Pandey and B. D. Malhotra, Biomed. Microdevices, 2008, 10, 757.

14 M. Wang, L. Wang, G. Wang, X. Y. Bai, T. Li, S. Gong and J. Li, Biosens. Bioelectron., 2004, 19, 575.
15 J. I. Pitt and A. D. Hocking 1997. Fungi and Food spoilage, 2nd ed.; Aspen Publishers: Gaithersburg, M.D.

16 X. H. Wang and S. Wang, Sensors, 2008, 8, 6045.

17 C. Zaied, S. Abid, S. Zorgui, C. Bouaziz, S. Houchane, M. Jomaa and H. Bacha, Food Control, 2009, 20, 218.

18 S. Amezqueta, E. Gonzalez-Penas, Murillo-Arbizu and L. D. Cerain, Food Control, 2009, 20, 326.

19 L. Monaci and F. Palmisano, Anal. Bioanal. Chem., 2004, 378, 96.

20 H. Valenta, J. Chromatogr., A, 1995, 815, 75.

21 S. H. Alarcon, G. Palleschi, D. Compagnone, M. Pascale, A. Visconti and I. Barna-Vetro, Talanta, 2006, 69, 1031.

22 J. C. C. Yu and E. P. C. Lai, React. Funct. Polym., 2005, 63, 171.

23 W. C. Tsai and C. K. Hsieh, Anal. Lett., 2007, 40, 1979.

24 R. Liu, Z. Yu, Q. He and Y. Xu, Food Control, 2007, 18, 872.

25 B. Prieto-Simon, M. Campas, J. L. Marty and T. Noguer, Biosens. Bioelectron., 2008, 23, 995.

26 C. M. Maragos and V. S. Thompson, Nat. Toxins, 1999, 7, 371.

27 A. Kaushik, P. R. Solanki, A. A. Ansari, S. Ahmad and B. D. Malhotra, Nanotechnology, 2009, 20, 055105.

28 A. Kaushik, P. R. Solanki, A. A. Ansari, S. Ahmad and B. D. Malhotra, Electrochem. Commun., 2008, 10, 1364.

29 R. Khan and M. Dhayal, Electrochem. Commun., 2008, 10, 492.

30 R. Khan and M. Dhayal, Biosens. Bioelectron., 2009, 24, 1700.

31 A. A. Ansari, A. Kaushik, P. R. Solanki and B. D. Malhotra, Bioelectroanalysis, 2010, 77, 75.

32 A. E. Radia, X. Munoz-Berbel, V. Latesc and J.-L. Martyc, Biosens. Bioelectron., 2009, 24, 1888.

33 X. P. Liu, Y.-J. Deng, X.-Y. Jin, L.-G. Chen, J.-H. Jiang, G.-L. Shen and R.-Q. Yu, Anal. Biochem., 2009, 389, 63.

34 J. R. Mackdonald, Impedance Spectroscopy, Emphasizing Solid Materials and Systems, John Willey \& Sons, New York, 1987.

35 A. J. Bard and L. R. Faulkner, Electrochemical Methods. Willey \& Sons, New York 2000.

36 A. Bardea, E. Katz and I. Willner, Electroanalysis, 2000, 12, 1097. 